\title{
MUJERES, HOMBRES Y VIDA FAMILIAR EN MÉXICO. PERSISTENCIA DE LA INEQUIDAD DE GÉNERO ANCLADA EN LA DESIGUALDAD SOCIAL
}

\author{
Olga Lorena Rojas \\ El Colegio de México
}

\section{RESUMEN}

En este trabajo se pretende reflexionar sobre la pertinencia analítica de la encrucijada entre la desigualdad social y el género, para dar cuenta del extenso abanico de posibilidades de las relaciones que establecen hombres y mujeres en la vida familiar en México. Para ello, se tomó en cuenta los resultados de diversas investigaciones, sobre todo de corte cualitativo y desde el campo de las ciencias sociales, que han reportado importantes modificaciones en la organización y el funcionamiento de las familias como resultado de los cambios sociales, demográficos, económicos y culturales experimentados en el país en las últimas décadas. Con este objetivo en mente, se pone a prueba la capacidad explicativa de algunas propuestas teóricas que se han desarrollado sobre las transformaciones en la vida íntima, producto de los cambios sociales y culturales que ha traído consigo la modernidad en las sociedades más desarrolladas.

\section{PALABRAS CLAVE}

México, vida familiar, género, desigualdad social

\section{ABSTRACT}

This paper offers a discussion about the analytical relevance of the crossroads between social inequality and gender to account for the wide range of possibilities of relationships between men and women in family life in Mexico. To do this, we consider the advances in social qualitative research undertaken in Mexico on the changes in the organization of family life, product of social, demographic, economic 
and cultural changes in recent decades, as well as some theoretical proposals that have been developed on the transformation of intimacy as a result of social and cultural changes that modernity has brought in more developed societies.

\section{KEY WORDS}

Mexico, family life, gender, social inequality 


\section{INTRODUCCIÓN}

Los abundantes aportes de la investigación social desarrollada recientemente en México - sobre todo a partir de acercamientos cualitativos-, respecto a las modificaciones ocurridas en los papeles desempeñados por hombres y mujeres en la organización y funcionamiento de las familias, nos llevan a reflexionar sobre la pertinencia analítica para el caso mexicano de las actuales discusiones teóricas en torno a las transformaciones en la vida íntima de las parejas y de las familias, producto de cambios sociales y culturales modernizadores en las sociedades más desarrolladas.

En este artículo analizamos el alcance de las transformaciones en las identidades y en las relaciones de género en la sociedad mexicana, la cual ha experimentado en poco tiempo importantes transformaciones modernizadoras en materia social, demográfica, económica y cultural, al tiempo que se encuentra caracterizada por la persistencia de profundas desigualdades socioeconómicas. Es esta realidad tan diversa y desigual la que nos lleva a plantear la necesaria articulación analítica entre la desigualdad social y el género, para así dar cuenta de los avances y también de las resistencias respecto a las inequidades existentes en las relaciones que establecen los hombres y las mujeres en el contexto familiar.

Los avances conseguidos en el país en materia escolar y laboral por la población femenina han propiciado, sobre todo en las jóvenes generaciones de mujeres urbanas, procesos de autonomía a partir de los cuales comienzan a cuestionar los modelos tradicionales de vida familiar, conyugal y parental. A estos procesos parecen sumarse los hombres citadinos y de generaciones más jóvenes, quienes muestran cada vez más interés por avanzar hacia el establecimiento de relaciones más íntimas con sus cónyuges y con sus hijos, basadas en la confianza, la equidad y la comunicación.

Sin embargo, estos procesos reflexivos, que constituyen un cambio generacional significativo, no se generalizan en la sociedad mexicana debido, en gran medida, a las disparidades y rezagos sociales, económicos y culturales que persisten todavía en amplios sectores poblacionales. De ello trataremos de dar cuenta en este trabajo.

\section{MODERNIDAD, CAMBIO SOCIAL}

\section{Y NUEVAS FORMAS DE INTIMIDAD}

Con la llegada de la Revolución industrial en el siglo XVIII, en las sociedades europeas se estableció una clara diferenciación entre los ámbitos público y privado. Esta separación permitió consolidar el desarrollo de la familia nuclear y, como parte de ella, una división sexual del trabajo que asignó roles específicos a mujeres y hombres. De esta manera, la función de las mujeres quedó reducida a la reproducción, en tanto que los varones convertidos en únicos proveedores de sus familiasdesempeñaban un trabajo remunerado fuera del ámbito doméstico (Giddens, 1998; Kaztman, 1991).

En este contexto social, el papel de las mujeres adquiere relevancia en el ámbito privado puesto que éstas quedaron a cargo del hogar y de la crianza infantil, en tanto que la relación entre padres e hijos se caracterizó por el distanciamiento físico y emocional. La sexualidad femenina quedó confinada al matrimonio y a la reproducción, mientras que la actividad sexual masculina aparecía encubierta por 
un doble modelo: la orientada a la reproducción y la asociada con el amor erótico. En esa época, los lazos matrimoniales estaban basados fundamentalmente en consideraciones económicas, al tiempo que se ejercían fuertes presiones sobre los cónyuges para constituir descendencias numerosas (Giddens, 1998).

Sin embargo, ya en el avanzado siglo XIX, como parte de los procesos sociales modernizadores, la formación de grandes descendencias dejó de ser una preocupación y se dio paso a la tendencia de limitar el tamaño de las familias. La formación de los lazos matrimoniales se fue desligando de los vínculos de parentesco y de los juicios de valor económico. Las nociones de amor romántico se difundieron en todos los órdenes sociales y se dio inicio al control de los nacimientos de los hijos. De esta manera, la reproducción comenzó a ser gobernada por el deseo de tener hijos cuando se deseaban realmente. Para la población femenina, el control de la natalidad significó una profunda transición en la vida personal puesto que la sexualidad quedó liberada de la reproducción ${ }^{1}$ (Giddens, 1998).

Los años sesenta del siglo XX marcaron un punto de inflexión en los anales de la familia en los países industrializados, puesto que el modelo masculino del proveedor único del sustento familiar dejó de ser la norma. Las tasas de participación de las mujeres casadas indicaban que la mayoría de las familias registraban a los dos cónyuges en la fuerza de trabajo (Kaztman, 1991). En estas sociedades modernizadas la emergencia del movimiento feminista, el incremento de la fuerza de trabajo

1 De hecho, esta sexualidad separada de su integración ancestral con la reproducción y el parentesco fue la condición previa de la revolución sexual de las décadas de los años sesenta del siglo pasado (Giddens, 1998). femenina y la proliferación de los hogares de doble proveeduría propiciaron que los hombres empezaran a revalorar su participación en la crianza de sus hijos. Producto de estas transformaciones comenzó a utilizarse el concepto del "nuevo padre" como resultado tanto de la necesidad de los hombres de desarrollar una relación más cercana y afectiva con sus hijos, como de la demanda femenina que necesitaba de mayor colaboración en el cuidado de los hijos mientras su desempeño en el mercado de trabajo se expandía (Engle y Breux, 1993). Esta modificación en el papel de los padres implicaría un cuestionamiento y ruptura con el ideal paterno patriarcal basado en un principio de jerarquía, caracterizado por el hombre que es fuerte, proveedor exclusivo, cabeza de familia y autoridad reconocida por su esposa y por los hijos (Olavarría, 2002).

Desde la teoría sociológica se señala que en las sociedades modernas estas transformaciones han venido a formar parte de un proceso de reconstitución de la intimidad que, en opinión de algunos, daría paso a la democratización de las relaciones interpersonales, de la vida diaria, de la esfera privada y de la vida personal. El origen de esta apertura democrática en las relaciones personales se encontraría en la emergencia de una "nueva relación" no sólo en el área de la sexualidad sino también en las relaciones entre padres e hijos, puesto que se reforzaría la idea de que los padres deben fomentar lazos emocionales con sus hijos, reconociendo su autonomía. Por consecuencia, al ponerse sobre la mesa de discusión la calidad de la relación de los padres con sus hijos, la intimidad debe sustituir el carácter autoritario de la figura paterna (Giddens, 1998). 
Conforme nos adentramos en el siglo XXI, este cambio y democratización de la vida personal, así como de las relaciones sociales, se estaría generalizando entre las sociedades modernas. Esta nueva forma de relación, es decir de "intimidad", sería evidencia de un deseo de mayor individualismo y de la emergencia de un patrón en el que las personas estarían ganando mayor control sobre sus vidas, en contraste con las limitadas opciones del pasado. ${ }^{2}$ Esta posibilidad de elección estaría acompañada de importantes transformaciones en las relaciones de género puesto que implicaría la ruptura con los significados tradicionales que se tenían de lo masculino, de lo femenino y también sobre la familia. Para gran parte de la población de las sociedades industrializadas, estos cambios ofrecerían la posibilidad de elegir la manera de vivir su vida, en el marco del establecimiento de relaciones más democráticas. Por ello se señala que la intimidad estaría siendo moldeada por el desarrollo de una ideología individualista, en la cual las opciones personales comienzan a proliferar antes que las grupales - y que estaban relacionadas con la parentela y con los linajes. Sin embargo, se reconoce que esta expansión de las posibilidades para elegir cómo ser y cómo relacionarse con los demás, conlleva incertidumbre e inseguridad, es decir una sensación de riesgo e inestabilidad (Plummer, 2003).

Es importante subrayar que la democratización de la vida íntima requeriría como condiciones la negociación y la discusión abierta de los miembros de la pareja, así como autonomía de cada uno

2 En esta nueva intimidad se encontraría subyacente una ética posmoderna que reconoce la importancia de la libertad, justicia, igualdad, cuidado y reconocimiento (Plummer, 2003). y libre comunicación como medio de expresión de las necesidades individuales. Este modelo de relación presupone igualdad y un acuerdo equitativo negociado para conseguir un equilibrio en las tareas y recompensas que cada uno juzgue aceptables en el marco de la vida matrimonial y familiar. Se trataría de construir una división del trabajo diferente a la heredada del pasado, que estaba basada sobre criterios preestablecidos e impuestos por recursos económicos desiguales que pesaban sobre la relación, así como por la preponderancia de la autoridad y el poder masculinos (Giddens, 1998).

Se considera que los cambios en la vida de las parejas, y en la relación entre padres e hijos, constituyen una parte fundamental de las profundas transformaciones que las sociedades modernas han experimentado durante los últimos tiempos y que atañen a la vida cotidiana de las familias. En este contexto, la calidad de los vínculos se habría modificado de forma sustancial, poniendo en evidencia el debilitamiento de las estructuras e instituciones tradicionales y patriarcales, tales como el género, la Iglesia y el parentesco, que gobernaban la vida y las opciones de las personas y de las familias. Estas transformaciones sociales y culturales han implicado una creciente autonomía individual y la emancipación económica de las mujeres, quienes demandan una mejor calidad en sus vínculos con los hombres y menos asimetría en las relaciones de género (Plummer, 2003).

En materia demográfica, en dichos países, estos cambios se han traducido en un incremento en la posposición de la edad a la primera unión, una mayor incidencia de la procreación en relaciones de cohabitación o extramaritales, además de un 
incremento en la disolución de las uniones, de las familias reconstituidas y de los hogares con doble proveedor, todos ellos elementos de lo que se denomina como la "segunda transición demográfica" (Lesthaeghe, 1995).

Sin embargo, otros teóricos que cuestionan el excesivo optimismo relacionado con la transformación de la vida íntima, consideran que no se puede pensar que estos cambios estén generalizados o que impliquen una ruptura total con el orden social patriarcal del pasado. De hecho, aún en las sociedades más industrializadas, la investigación empírica ha observado que esta transición no ha sido tan tersa ni directa. En la vida diaria de las personas, de las parejas y de las familias, los ideales y los esfuerzos prácticos por una mayor igualdad e intimidad entre hombres y mujeres coexisten todavía con inequidades y estereotipos de género (Jamieson, 1999).

Por otra parte, se señala que la vida de la población de mayor edad en las sociedades desarrolladas, al igual que la mayoría de las poblaciones de las sociedades consideradas en desarrollo, todavía está regida por la tradición a pesar de que han empezado a entrar en el mundo de la modernidad. En estas sociedades tradicionales difícilmente existe la noción de que las personas, como seres individuales, tienen acceso a opciones. Las intimidades tradicionales continúan siendo la norma de muchas comunidades en las cuales la gente vive rodeada de sus familias, y cuya existencia permanece regida por órdenes sociales fuertemente patriarcales y/o religiosos que indican con quién se debe contraer matrimonio, cuándo tener hijos, qué tipo de sexualidad ha de ejercerse; en suma, cómo vivir la vida, restringiendo las posibilidades de elección. El confinamiento en estrechos y específicos roles es más acentuado, y claramente visible, en sistemas sociales basados en la exclusión y marginación, como producto de desigualdades extremas como las de género, clase social, étnicas y generacionales (Plummer, 2003).

En esos contextos tradicionales los sueños de amor romántico han terminado por conducir a las mujeres a una sujeción doméstica. El carácter subversivo del amor romántico queda frustrado por la asociación del amor con el matrimonio y la maternidad, así como por la idea de que el amor verdadero, una vez encontrado, es para siempre. El resultado termina siendo - muy seguramente- años de infelicidad en los que un matrimonio efectivo, aunque no gratificante, se encuentra sustentado por una estricta división del trabajo entre los sexos y con el dominio del esposo ${ }^{3}$ (Giddens, 1998).

Al estar regidas por el autoritarismo, este tipo de relaciones matrimoniales $-\mathrm{y}$ cualquier otro tipo de relación, incluida la existente entre padres e hijos-, se caracteriza por ser jerárquica. Sin embargo, este orden genera cierta seguridad a las personas implicadas en ellas, puesto que provee de una normativa y un conjunto de significados compartidos por todos y a partir de los cuales se establecen expectativas y roles que cada quien debe cumplir en materia de género, sexualidad y reproducción (Plummer, 2003).

3 En este contexto, resalta la importancia del confinamiento de la sexualidad femenina al matrimonio para constituir el distintivo de una mujer "respetable". Esto ha permitido a los hombres mantener su distancia del ámbito de la intimidad y a las mujeres mantener la condición de casada como objetivo primario (Giddens, 1998). 
En este orden de ideas, conviene señalar que los prolongados procesos de transformaciones sociales y económicas ocurridos en los países de industrialización temprana (considerados desarrollados) contrastan con la relativa rapidez con que, en las sociedades latinoamericanas, se produjeron las transformaciones socioeconómicas modernizadoras que tuvieron importantes efectos sobre la organización familiar. En este intenso proceso de cambio, destaca la acelerada industrialización y urbanización registrada a principios del siglo XX en América Latina, la cual propició que el ajuste de las estructuras familiares a las nuevas circunstancias estuviera sujeto a presiones contradictorias, particularmente entre las familias migrantes del campo a la ciudad. Por un lado, la inercia de los patrones culturales tradicionales y el traspaso de pautas de fecundidad rurales a las ciudades empujaron hacia el mantenimiento de la mujer en el hogar y la asignación del papel de proveedor a los varones. Y por otro lado, el intenso crecimiento de las ciudades - sobre todo a partir de la década de los años cincuenta del siglo pasadocontribuyó a la perpetuación de la desigualdad social y a la ampliación de la población en situación de pobreza en los márgenes de los nuevos contextos urbanos (Kaztman, 1991; Olavarría, 2004).

Asimismo, la crisis económica de los años ochenta del siglo XX en las sociedades latinoamericanas, además de las políticas de ajuste, la reformulación del papel del Estado, la creciente precarización del empleo masculino - tanto en los montos de su remuneración como en la estabilidad de sus puestos-, contribuyeron a deteriorar severamente la capacidad de los hombres de estratos populares urbanos para mantener a sus familias. Lo anterior dio paso a que se incrementara de forma considerable la tasa de participación femenina en el mercado laboral, tanto formal como informal, para complementar los insuficientes ingresos de sus compañeros (Olavarría, 2004).

Aunado a ello han de tenerse en cuenta los avances en los niveles educativos de la población y la rápida reducción de la fecundidad, que ampliaron la disponibilidad laboral de las mujeres casadas. Todos estos procesos han contribuido a transitar del modelo familiar de "hombre proveedor" al de familias de doble ingreso, poniendo en cuestionamiento el papel del varón como proveedor único en las familias, así como la centralidad del poder y la autoridad en la figura del jefe del hogar (Arriagada, 2010; Kaztman, 1991; Olavarría, 2004).

Si bien la proliferación de hogares de dos proveedores en diversos países de América Latina ha obligado a una flexibilización del sistema de roles familiares, es conveniente señalar que en estos procesos de cambio se observa una superposición de modos tradicionales de simbolizar la autoridad y la división sexual del trabajo, junto con negociaciones por una mayor igualdad entre hombres y mujeres. Por ello se advierte la necesidad de revisar la distancia que existe entre los procesos reales de cambio y los procesos de democratización de las familias $^{4}$ (Olavarría, 2004; Schmukler, 1998).

4 La búsqueda de una democratización en las familias latinoamericanas implicaría generar en los hombres actitudes más flexibles con respecto a su papel en el hogar y el establecimiento de mayor igualdad en varios aspectos de la vida familiar, tales como la división sexual del trabajo doméstico, las decisiones familiares, la generación y el control de los ingresos, la distribución de los recursos familiares, las prácticas anticonceptivas de la pareja y la realización de 
Puede decirse que el proceso modernizador o de desarrollo social, económico y cultural en América Latina ni ha seguido una trama lineal y uniforme, ni se ha generalizado. Por ello, no puede hablarse en sentido estricto de un proceso de "modernización", sino más bien de la coexistencia de diversos patrones sociales y culturales, algunos conservadores y otros emergentes, de los cuales surgen transformaciones en la organización de la vida familiar y conyugal, en las cuales persisten contradicciones en las concepciones, las conductas y, por supuesto, en el orden de género (Nehring, 2005). Si bien la región latinoamericana se encuentra inmersa en los procesos globalizadores que acentúan la interculturalidad moderna, siempre existen resistencias a las fuerzas que minan la autonomía de las tradiciones locales. Hay un rechazo a aceptar estas formas de hibridación porque generan inseguridad en las culturas y conspiran contra la autoestima etnocéntrica. Por ello, puede decirse que en América Latina las tradiciones aún no se han ido y la modernidad no acaba de llegar (García Canclini, 1990).

\section{MÉXICO: UN ESCENARIO DE SIGNIFICATIVOS CAMBIOS SOCIALES Y CULTURALES PERO NO GENERALIZADOS}

México, como toda la región latinoamericana, experimentó transformaciones económicas y sociales muy intensas en un periodo relativamente corto. Como resultado de ese proceso de modernización, la sociedad mexicana dejó de ser predominantemente rural ${ }^{5}$ para ser eminentemente actividades extradomésticas (Kaztman, 1991; Schmukler, 1998). 5 A mediados del siglo pasado la población rural abarcaba el $57 \%$ del total nacional, en tanto que en 1990 constituía tan sólo el $34.4 \%$, mientras que a principios del siglo XXI urbana e industrializada. Así mismo, en muy poco tiempo se consiguieron avances sustantivos en la masificación de la educación y en la elevación de los niveles educativos de la población en general, además de un acceso generalizado a los servicios de salud y de planificación familiar. ${ }^{6}$ Todo ello tuvo como resultado un significativo descenso de la fecundidad, ${ }^{7}$ la disminución del tamaño de los hogares 8 y un incremento de la participación femenina en el mercado de trabajo. ${ }^{9}$

A estos cambios se agregó una transformación social y cultural, nutrida por los procesos de secularización, modernización y globalización, que provee de discursos sobre la igualdad y la libertad, así como de diferentes patrones y concepciones sobre cómo debe ser la vida sexual, en pareja, en

decreció al 31\% (INEGI, 2005).

6 En 1976, una de cada tres mujeres en edad fértil regulaba su fecundidad mediante el uso de algún método anticonceptivo; para 1982 esta proporción se incrementó hasta alcanzar el $48 \%$, en tanto que hacia 1995 ya era del orden de $66.5 \%$ (Hernández, 2001). Se estima que actualmente casi el $80 \%$ de las parejas regula su fecundidad con algún anticonceptivo (Rojas, 2008a).

7 El significativo descenso de la fecundidad constituye una de las transformaciones demográficas más relevantes registradas en México durante los últimos 30 años del siglo pasado. En los años sesenta del siglo XX, las mujeres mexicanas tenían en promedio siete hijos, en 1986 ya habían reducido su fecundidad a 3.8 hijos, para 1998 era del orden de 2.6 hijos, mientras que en la actualidad su fecundidad se ha reducido a poco más de dos hijos. En esta importante transición de la fecundidad, las mujeres mexicanas han desempeñado un papel protagónico, pues sobre ellas ha descansado gran parte de la práctica anticonceptiva moderna que ha permitido espaciar y limitar la descendencia (CONAPO, 2006).

8 El tamaño promedio de los hogares en 1970 era de 5.3 miembros, en tanto que hacia 2010 era de 3.9 (García y Oliveira, 2014).

9 La tasa de participación laboral femenina en los años setenta era del $17 \%$, a mediados de los años 90 se incrementó al $30 \%$ y actualmente alcanza el 44\% (García y Oliveira, 2014; Rodríguez y García, 2014). 
familia, y la educación de los hijos; herramientas accesibles principalmente para la población urbana y con elevados niveles de escolaridad (Amuchástegui, 2001; Esteinou, 2008; Szasz, 1998a, 1998b, 2001). ${ }^{10}$

Por otro lado, es importante llamar la atención sobre la relatividad de estos cambios en la sociedad mexicana. En materia sexual y reproductiva el discurso religioso coexiste todavía con la información científica difundida en las escuelas, las políticas de población, los medios de comunicación y las intensas campañas de planificación familiar y de prevención del VIH/sida. Como resultado, las concepciones y las prácticas sexuales en el país están adquiriendo significados nuevos y diversos, sobre todo entre la población joven y de ámbitos urbanos. Por ello el contexto cultural mexicano es considerado hoy como heterogéneo, complejo e híbrido (Amuchástegui, 2001; Nehring, 2005; Szasz, 2001, 2008).

El conjunto de estas transformaciones ha impactado desde luego en la estructura y el funcionamiento cotidiano de las familias mexicanas, al tiempo que ha contribuido a modificar los significados y los comportamientos sexuales y reproductivos de la población y, por tanto, algunas dimensiones de las relaciones y de las identidades de género. En los sectores sociales mejor posicionados se están registrando procesos de redefinición de las imágenes sociales sobre lo femenino y lo masculino (Ariza y Oliveira, 2004; García y Oliveira, 2005, 2006; Oliveira, 1998).

10 Es muy probable que gracias a este mayor acceso a discursos y bienes culturales, la población de la clase media construya su identidad individual de forma más reflexiva con discursos y repertorios más igualitarios y libertarios que el resto de la población (Esteinou, 2008).
Se señala, por estos motivos, que en el contexto particular mexicano, la constitución de las relaciones de género tendría que ser entendida a partir de la consideración de procesos de modernización y de globalización cultural, pero también a partir de la mezcla e interpenetración de elementos culturales heterogéneos provenientes de fuentes internas y externas. Las relaciones de género en México sobre todo desde comienzos de la década de 1980 se han vuelto mucho más complejas, puesto que ciertos patrones tradicionales coexisten con nuevas alternativas accesibles para la población mexicana en materia de creencias y prácticas (Nehring, 2005).

La década de los años ochenta en México constituyó un parteaguas que marcó el comienzo de un incremento sistemático en la incorporación de las mujeres al mercado de trabajo. ${ }^{11}$ Este hecho ha tenido importantes consecuencias en el funcionamiento de las familias puesto que se han configurado las condiciones para un cambio en la estructura de roles entre hombres y mujeres, así como en la relación de poder existente y que había concedido amplias prerrogativas en la toma de decisiones a los varones. ${ }^{12}$ La actividad económica de las mujeres mexicanas,

11 A partir de los años ochenta, las subsecuentes y recurrentes crisis económicas, además de la reestructuración productiva y el impulso a la terciarización económica, han venido a configurar un panorama de incertidumbre e inestabilidad al erosionar el funcionamiento de los mercados laborales. En las décadas más recientes se han profundizado las desigualdades sociales ya existentes, así como la precariedad laboral, cuestiones que generan fuertes presiones y restricciones en el nivel de vida de las familias (Ariza y Oliveira, 2004; Rendón, 2004). 12 Aunque sigue siendo predominante el modelo familiar de tipo nuclear, se han incrementado los hogares con jefatura femenina, los hogares unipersonales y aquellos de doble proveedor, todos estos arreglos restan importancia de manera creciente al modelo tradicional del jefe varón proveedor único (Ariza y Oliveira, 2004). 
sobre todo de las casadas, ${ }^{13}$ fuera del hogar, ha favorecido una flexibilización en la división del trabajo familiar que en ocasiones se traduce en un incremento de la participación masculina en el ámbito doméstico, sobre todo en lo que se refiere al cuidado de los hijos (García y Oliveira, 2006; Rojas, 2008b; Rojas y Martínez, 2014).

La incorporación masiva de las mujeres al trabajo extradoméstico ha sido posible gracias al aumento de sus niveles de escolaridad, ${ }^{14}$ al descenso de la fecundidad, además del aumento de la edad al matrimonio, ${ }^{15}$ todo lo cual ha propiciado que actualmente las mujeres mexicanas puedan dedicar menos años de sus vidas y menos horas diarias a la crianza de sus hijos que antes. Además, al aumentar los divorcios y las separaciones, muchas mujeres se convierten en jefas de familia y proveedoras del sustento de sus hijos. El incremento sustantivo de las tasas de participación femenina en el trabajo extradoméstico y la tendencia generalizada al descenso de las tasas masculinas reflejan claramente

13 A pesar de que las mujeres que son esposas del jefe del hogar tienen un menor nivel de actividad económica que las jefas de hogar, las hijas u otras parientes, duplicaron su presencia económica entre 1991 y 2011, de 28\% a 45\% (García y Pacheco, 2014). Por otro lado, se ha documentado que en el último decenio del siglo pasado, las familias nucleares con hijos y de doble proveeduría aumentaron de $9.3 \%$ a $19 \%$, en tanto que las de proveedor varón exclusivo disminuyeron de $59.9 \%$ a $49.4 \%$ (López y Salles, 2006).

14 Las mujeres mexicanas han aumentado considerablemente su acceso a los sistemas educativos. En 1970 tenían en promedio 3.7 años de escolaridad, en tanto que hacia 1999 alcanzaban 7.7 años. Su acceso no solamente se ha ampliado en los niveles básicos, también han incrementado su incorporación a la educación superior. No obstante, las mujeres rurales todavía tienen importantes desventajas con respecto a sus pares urbanas (CONAPO, 2014).

$15 \mathrm{La}$ edad promedio a la primera unión conyugal de las mujeres aumentó de 18.8 años en la década de los setenta, a 23.1 años en 1997 (Rendón, 2004). la pérdida de la importancia del modelo familiar de un proveedor único varón en el país (Rendón, 2004).

Esta creciente participación económica femenina en el mercado de trabajo ha tenido consecuencias importantes en la manera de pensar de las mujeres, sobre todo de clase media, puesto que ahora su posición social e identidad ya no están ancladas al matrimonio y a la procreación. Para ellas tener un trabajo es tan importante como casarse y conformar una familia. Este hecho está produciendo una redefinición de roles y, por lo tanto, procesos de negociación entre los cónyuges que derivan en tensiones y conflictos que pueden conducir en ocasiones a la disolución de los matrimonios (Esteinou, 2008; Nehring, 2005).

En efecto, en el país las bases del matrimonio están cambiando puesto que las personas evalúan con más frecuencia su matrimonio y sus vidas como pareja en función de las satisfacciones emocionales y afectivas que pueden obtener. Por ello está perdiendo peso la influencia de la familia, de la parentela y de la normativa religiosa, todas ellas instituciones patriarcales. Al parecer, hombres y mujeres comienzan a percibir que tienen mayor control sobre sus vidas y por ello cuestionan las ideas precedentes sobre la familia como institución reproductora de la especie que dejaba en un segundo plano la búsqueda del placer sexual y de la felicidad en la vida conyugal. Esto habla de la existencia de mayores niveles de libertad de las parejas puesto que hombres y mujeres pueden decidir, con mayor autonomía que antes, romper la unión conyugal. ${ }^{16}$

16 En el país las uniones matrimoniales se han caracterizado a lo largo del tiempo por su marcada estabilidad, puesto que históricamente se han observado bajas tasas de divorcio y de separación, sobre todo si se compara con la experiencia de 
Sin embargo, hay que señalar que el divorcio en México es más frecuente en ámbitos urbanos y entre las generaciones más jóvenes, lo cual apunta hacia procesos de individuación relacionados con importantes cambios culturales registrados en estos sectores sociales ${ }^{17}$ (Esteinou, 2008; López y Salles, 2006).

Actualmente, y en buena medida a raíz de su avance en materia de escolaridad y de su relevante desempeño en la fuerza de trabajo, las mujeres han empezado a cuestionar su papel de sumisión frente a los hombres, e intentan establecer relaciones de género más igualitarias en el ámbito conyugal. Estas resistencias femeninas respecto a las estructuras de roles y de autoridad se presentan con mayor frecuencia entre las mujeres más jóvenes, con mayor escolaridad, asalariadas, que controlan una mayor cantidad de recursos y que asumen un mayor compromiso con el trabajo fuera del hogar (García y Oliveira, 1994; Oliveira, 1994, 1998).

Con ello nos damos cuenta de que estos cambios no abarcan a la totalidad de la sociedad mexicana; en realidad se ubican principalmente entre los estratos sociales con mejores condiciones de vida, mayores niveles educativos y de ámbitos

otros países, aún de la región latinoamericana. Sin embargo, la disolución de las uniones ha registrado recientemente un aumento puesto que en los años cincuenta la tasa de divorcios era apenas del 4.4\%, en tanto que para el año 2007 alcanzaba el $13 \%$ y, actualmente, cerca del 14.5\%. (García y Rojas, 2004; López y Salles, 2006; Ojeda, 1989).

$17 \mathrm{Al}$ respecto, se señala que el aumento en la escolaridad y en la participación laboral de las mujeres son factores que pueden facilitar, hoy más que antes, la ruptura de uniones conyugales no satisfactorias y la constitución posterior de hogares independientes (García y Rojas, 2004). Además, se ha observado que entre las mujeres profesionistas existen proporciones más altas de divorcios que entre los hombres (López y Salles, 2006). urbanos. Entre la población de sectores obreros, populares, rurales e indígenas se observan resistencias a la posibilidad de modificaciones en la vida familiar y conyugal, prevaleciendo relaciones muy inequitativas, sobre todo en lo que se refiere la división sexual del trabajo y a la esfera de la sexualidad (Ariza y Oliveira, 2004; Bellato, 2001; García y Oliveira, 1994; González, 2014; Oliveira, 1994, 1998).

A partir de todos estos elementos podemos decir que si bien la sociedad mexicana ha experimentado un proceso de modernización socioeconómica y de diversificación cultural profundo, estos cambios no han alcanzado a modificar las estructuras de género en todos los grupos sociales. Ahora bien, este alcance diferenciado en las transformaciones sociales y culturales ha producido una mayor complejidad, así como una multiplicidad de formas de funcionamiento familiar y de relación entre hombres y mujeres.

Nos interesa por ello profundizar en el análisis de los alcances de las modificaciones en los papeles femeninos y masculinos en la vida familiar tomando en consideración la desigualdad social persistente en el país. ${ }^{18}$ Queremos reflexionar hasta dónde las mujeres y los hombres mexicanos han ido abandonando los ideales patriarcales y en su lugar tratan de conformar relaciones más democráticas y equitativas en el funcionamiento cotidiano de las familias. Para llevar a cabo este análisis tomamos

18 México es un país donde la pobreza y la desigualdad social se han manifestado de manera persistente y generalizada. Prueba de que el patrón distributivo mexicano es concentrador y excluyente, es que en 2012 vivían en la pobreza 53.3 millones de mexicanos, en tanto que 11.5 millones estaban en condiciones de miseria absoluta (CONEVAL, 2012; Mora y Oliveira, 2014). 
como eje argumentativo la desigualdad social y económica prevaleciente en el país.

TRANSFORMACIONES Y PERSISTENCIAS EN LAS RELACIONES DE GÉNERO: UN ANÁLISIS POR SECTORES Y ESTRATOS SOCIALES

Antes de que entraran en un proceso de transformación, las familias mexicanas eran unidades con una clara y estricta división del trabajo y de roles. ${ }^{19}$ Estaban orientadas y centradas en los hijos, quienes eran el centro de atención y preocupación de ambos padres. Las madres, con una actitud abnegada y sacrificada, se hacían cargo de las tareas domésticas en función de las necesidades de los hijos y del esposo. Los padres se centraban en cumplir con el ideal paterno a partir del cual lo primordial era asumir su papel como proveedores únicos para asegurar el sustento familiar y la educación de sus hijos. Su presencia en el hogar generaba temor y respeto; el vínculo con sus cónyuges y con sus hijos estaba regido por una fuerte jerarquía y una clara distancia emocional que impedía el desarrollo de relaciones más igualitarias e íntimas. La relación de los hijos con este tipo de padres estaba caracterizada por la obediencia y

19 En la época de expansión económica, de los años cuarenta a los setenta del siglo pasado, se registró un periodo de auge y declive del modelo de industrialización por sustitución de importaciones. En su fase expansiva se registraron altas tasas de crecimiento económico, constituyendo una época de bonanza y de importante movilidad social de la población. En ese tiempo predominaron estructuras familiares nucleares y numerosas, encabezadas por el jefe varón como proveedor único. La participación económica femenina era muy baja debido a las fuertes cargas familiares para las mujeres, sus escasos niveles de escolaridad y las pocas oportunidades que había para ellas en el sector industrial, que estaba fuertemente masculinizado (Ariza y Oliveira, 2004). la subordinación. Era frecuente que estos padres educaran a sus hijos con una disciplina muy estricta y recurrieran al castigo severo para corregir sus comportamientos (Esteinou, 2008; Rojas, 2008b).

En este modelo de familia, la maternidad constituía el eje organizador de las vidas de las mujeres y solamente a través de ella podían obtener legitimidad y reconocimiento social (Nájera, et al., 1998). En contraposición, el ideal paterno, que corresponde al modelo de masculinidad dominante, determinaba para los hombres adultos la obligación de trabajar de manera remunerada, constituir una familia, tener hijos, ser la autoridad y los únicos proveedores del hogar. La paternidad - en el sentido de concebir y engendrar hijos- era uno de los pasos fundamentales del tránsito de la juventud a la adultez (Olavarría, 2002). Esta figura tradicional del padre se caracterizaba por centrar su participación en el cumplimiento de la responsabilidad por el bienestar físico y material de sus hijos, así como en la enseñanza y preparación de los mismos como futuros proveedores (Gutmann, 1996; HernándezRosete, 1996; Vivas, 1996).

Sin embargo, de acuerdo con los hallazgos de la reciente investigación social, se sabe que este panorama está en vías de transformación puesto que los cambios económicos y sociales ocurridos en México, relacionados con el aumento de la participación laboral femenina, los avances en los niveles educativos de la población y la creciente precarización laboral de la población masculina, han contribuido a reestructurar los arreglos laborales de los hogares ${ }^{20}$ y la relación de poder

20 La modificación de la estructura sectorial del empleo, resultante de la nueva estrategia económica desarrollada a partir 
entre hombres y mujeres (García y Oliveira, 1994, 2006; Oliveira, 1998).

Hay que señalar que si bien la creciente actividad económica femenina ha ampliado sus aportaciones monetarias dirigidas a satisfacer las necesidades de consumo básico de los hogares - que podría significar un cambio importante en los papeles masculinos y femeninos-, ello no ha implicado necesariamente una modificación profunda de la división sexual del trabajo, de forma que se garantice una responsabilidad equitativa de hombres y mujeres. De hecho, la tensión entre la inserción laboral femenina y las - cada vez mayores - dificultades que enfrentan los varones para desempeñarse como proveedores exclusivos del sustento familiar, es vivida en forma conflictiva en no pocos hogares mexicanos (García y Oliveira, 1994).

Diversas investigaciones sociales han constatado que los varones se involucran apenas de manera esporádica en las labores de la casa, y cuando se logra su participación muchas veces se debe a la presión ejercida por sus cónyuges y, sobre todo, cuando las esposas desempeñan una actividad económica extradoméstica (García y Oliveira, 1994; Oliveira, 1998; Rojas, 2010; Rojas y Martínez, 2014).

de los años ochenta del siglo XX, trajo aparejada una creciente feminización de la fuerza de trabajo, puesto que el sector más dinámico en la generación de empleos fue el de los servicios, caracterizado tradicionalmente por una importante presencia de mujeres. En contraste, las actividades con predominio de la fuerza de trabajo masculina vieron mermada su capacidad para generar empleos al ser afectadas por la competencia externa y la reestructuración productiva. Este es el caso de la agricultura, la industria extractiva y una parte de la industria manufacturera orientada al mercado interno (Rendón, 2004).
Sin embargo, también se cuenta con evidencias de que entre las jóvenes generaciones masculinas hay un incremento de su participación en los cuidados y la crianza de sus hijos. Esta mayor participación en la formación y educación de los pequeños ha permitido la conformación de relaciones más cercanas y afectuosas entre padres e hijos. Al parecer, estos hombres intentan ampliar su papel más allá de la mera procreación de los hijos y de la proveeduría del ingreso familiar (García y Oliveira, 2006; Gutmann, 1996; Hernández-Rosete, 1996; Nava, 1996; Rojas, 2007, 2008b).

Hay que tener en consideración que si bien esta re-significación y ampliación del papel de los hombres jóvenes mexicanos en la vida doméstica puede tener los alcances de un cambio generacional, en esta transformación deben tomarse en cuenta los matices existentes con respecto a la desigualdad social del país.

\section{Los sectores populares urbanos,} rurales e indigenas

Cuando la investigación social se ha enfocado en los sectores sociales residentes en el campo y en comunidades indígenas, así como en contextos empobrecidos urbanos, se ha observado que las transformaciones en la división intrafamiliar del trabajo han sido lentas, debido a que todavía existe un fuerte arraigo de concepciones tradicionales respecto a los papeles masculinos y femeninos. Hay evidencias de que entre las mujeres de estos sectores sociales todavía está vigente la idea de que ellas son responsables del trabajo doméstico, en tanto que sus cónyuges lo son de la manutención del hogar (González, 2014; Oliveira, 1994, 1998). 
En estos sectores sociales, las mujeres y los varones todavía no han incorporado de manera generalizada en su imaginario de posibilidades el trabajo remunerado femenino, de tal suerte que prevalece todavía una reafirmación del ideal paterno que cumple con el papel tradicional del hombre como proveedor, al que corresponde su contraparte femenina de la mujer dedicada exclusivamente al hogar y a los hijos.

La idea de que la familia como grupo se antepone a las decisiones individuales se encuentra todavía muy arraigada en estos contextos sociales. La influencia de los parientes en la vida de las parejas y de las familias restringe el desarrollo de la libertad individual y contribuye a reproducir las desigualdades de género que se derivan de las rígidas jerarquías que estructuran la vida y las relaciones de pareja y familiares (Esteinou, 2008; García y Oliveira, 1994, 2006).

Para los hombres de estos grupos sociales ser proveedor y, por tanto, cabezas de familia, sigue constituyendo dimensiones fundamentales de su identidad de género. Por eso manifiestan estar en fuerte desacuerdo con la incorporación de sus cónyuges al mercado de trabajo y no dan su autorización para que ellas salgan de casa para trabajar porque esto implica, en su opinión, el descuido de sus hijos y de sus hogares. Por ello, a pesar de los elevados niveles de pobreza y de la creciente necesidad de la participación económica femenina, las mujeres de estos sectores sociales todavía tienen que pedir permiso a sus maridos para trabajar. Lo anterior refleja la situación de subordinación y obediencia en la que todavía se encuentran, ya que no pueden pasar por alto la autoridad de sus esposos como jefes del hogar. El empleo remunerado de estas mujeres es percibido por sus maridos como una amenaza a su desempeño masculino, pero sobre todo como evidencia social de su incapacidad para proveer con sus ingresos el sustento de la familia (García y Oliveira, 1994; González, 2014; Núñez, 2007; Rojas, 2008b, 2010).

En estos contextos sociales es común que las mujeres que colaboran con su trabajo a los ingresos familiares afirmen con frecuencia que su contribución económica al hogar no es esencial, aunque lo sea en la práctica. A veces la situación es más compleja ya que cuando las mujeres perciben ingresos semejantes o superiores a los de sus cónyuges, los varones pueden sentir amenazado su papel como proveedores principales de sus hogares, su autoridad en la familia y, por tanto, su masculinidad, de tal suerte que en estos casos las relaciones familiares se hacen más opresivas e incluso violentas para las mujeres ${ }^{21}$ (González, 2014; Oliveira, 1998; Rojas, 2010).

Se sabe, por otro lado, que la desigualdad de género tan acentuada entre las familias de los estratos sociales de bajos ingresos y entre las generaciones mayores se refleja también en las prácticas y valoraciones sexuales en el contexto de la vida marital. Entre los hombres de estos estratos y edades, prevalecen normativas muy conservadoras de género y sobre la sexualidad, puesto que consideran que ellos tienen necesidades

21 Diversas encuestas especializadas en violencia doméstica han dado cuenta de que las mujeres que tienen un mayor riesgo de sufrir diferentes formas de violencia (emocional, económica, física y sexual) por parte de su pareja, son las que participan en el mercado de trabajo en comparación con las que son amas de casa (García y Oliveira, 2014). 
sexuales que las mujeres deben atender en virtud del vínculo conyugal y porque ellos cumplen cabalmente con sus obligaciones como esposos responsables y trabajadores. En este contexto, la atención sexual de las mujeres es considerada como un reconocimiento y retribución a su hombría, al hecho de que se es un hombre que cumple con la proveeduría de su hogar. De esta manera, el vínculo marital se sostiene a partir del intercambio de trabajos entre los cónyuges: mientras ellos realizan el trabajo de mantener, ellas llevan a cabo el de atender. Dicho intercambio genera marcadas desigualdades de género en el ejercicio de la sexualidad (Núñez, 2007; Szasz, 2008).

La situación de subordinación de las mujeres de estos sectores sociales concuerda con la posición y la imagen masculina preponderante del padre como máxima autoridad. En este modelo, la paternidad y el trabajo son elementos constitutivos y fundamentales del ideal masculino, puesto que otorgan un objetivo a la existencia y a la vida cotidiana de los hombres. Procrear a sus hijos después del matrimonio contribuye a probar su virilidad, además de que les permite conformar una familia que depende de ellos. De esta forma, sus vidas personal y conyugal, así como su actividad laboral, adquieren sentido. La paternidad significa entonces asumir una gran responsabilidad al ser cabezas de familia y conformar un hogar del cual son responsables (Bellato, 2001; Gutmann, 1996; Módena y Mendoza, 2001; Rojas, 2008b).

Cuando se ha estudiado en particular las actitudes de los padres de las familias de sectores populares urbanos, se ha detectado entre los más jóvenes un esfuerzo por modificar la relación que establecen con sus hijos y con sus compañeras. En particular, cuando se trata de sus pequeños, los jóvenes padres desean generar espacios de mayor cercanía, comunicación y afecto, intentando dejar a un lado las formas fuertes y severas para disciplinarlos, así como la muy escasa comunicación que ellos padecieron de sus propios padres cuando fueron niños. Sin embargo, la precariedad de su condición social y económica, además de su preocupación por brindar bienestar físico y material, así como un buen nivel de escolaridad a sus hijos, les lleva a tener ocupaciones con largas jornadas de trabajo e incluso dos empleos. A causa de sus horarios de trabajo, buscan compensar la escasez de tiempo para estar con sus hijos tanto con una mayor intensidad en la relación a través del juego, como con la expresión abierta de su afecto. Sin embargo, estos jóvenes padres se relacionan de manera preferente con sus hijos varones antes que con sus hijas, porque consideran que la formación y educación de sus pequeñas es una tarea que corresponde a la madre y no al padre (Rojas, 2007, 2008b).

Se ha notado, por otra parte, que su involucramiento en la crianza y los cuidados de sus hijos es relativo, pues es mayor cuando sus esposas salen de casa para trabajar y prácticamente nulo cuando ellas son amas de casa. Este avance en las actitudes masculinas de las jóvenes generaciones coincide con las nuevas actitudes de las jóvenes mujeres de estos sectores sociales, quienes empiezan a defender activamente sus derechos a fin de cambiar los patrones tradicionales en las relaciones de pareja (Oliveira, 1998).

Sin embargo, es importante señalar que el hecho de que las cónyuges de estos varones trabajen 
fuera de casa, no las exime de la responsabilidad de la crianza y el cuidado de los hijos, ni de los quehaceres domésticos. Son precisamente las características que conlleva en muchas ocasiones su empleo informal y la flexibilidad de sus horarios laborales lo que permite que ellas desempeñen esta doble jornada. Y, al mismo tiempo, las ventajas que este tipo de actividad económica femenina ofrece - para resolver no solamente la cuestión de la crianza de los hijos sino, sobre todo, la realización de las tareas domésticas-, permiten que los padres asuman menor responsabilidad que sus compañeras respecto a estas cuestiones (García y Oliveira, 1994, 2006; Rojas, 2007, 2010; Rojas y Martínez, 2014).

Por otro lado, cuando la investigación social analiza en particular el nivel de autonomía de las mujeres rurales con respecto a sus pares urbanas, se ha encontrado que las primeras todavía mantienen rezagos importantes, aún si se consideran los avances logrados en sus niveles de escolaridad, en su participación en el empleo remunerado y en el descenso de su fecundidad. En estos contextos destacan los casos de las mujeres más jóvenes, con escolaridad mayor a la secundaria y que se insertan en el mercado de trabajo como asalariadas por tener algunas mejoras en su libertad de movimiento, en la participación en la toma de decisiones familiares y en el control de algunos recursos económicos (López, 2014).

Estos logros paulatinos en la situación de las mujeres rurales se deben, en buena medida, al fenómeno denominado 'feminización del campo mexicano' y que hace referencia al conjunto de procesos sociodemográficos, económicos y sociales que forman parte de lo que se conoce como la 'nueva ruralidad'. Uno de los principales rasgos de esta nueva situación del campo es que las actividades agropecuarias han de dejado de ser la principal fuente de subsistencia de un gran número de familias rurales para dar lugar a la combinación de una amplia gama de actividades de las cuales los miembros de dichas familias obtienen los recursos para sobrevivir. Las poblaciones del campo ahora asumen características de pequeñas ciudades en las que se expanden los servicios, las pequeñas empresas familiares y las maquiladoras. A estos cambios se une el complejo y prolongado proceso migratorio que ha contribuido a vaciar de su población masculina a comunidades enteras. Todas estas transformaciones estructurales están contribuyendo a modificar el papel desempeñado por las mujeres en los pueblos y en las familias campesinas. Por un lado, la pérdida de valor de la tierra — comúnmente asociada con la propiedad y herencia masculinas - contribuye a crear condiciones diferentes y propicias para los cambios en la posición femenina. Y por otro lado, las mujeres están siendo reclutadas como mano de obra remunerada en las estructuras ocupacionales locales, además de que también se hacen cargo de la parcela familiar y de la administración de las remesas en ausencia de los maridos migrantes (Arias, 2013; González, 2014).

Cuando se estudian los actuales movimientos migratorios de las mujeres provenientes del campo, se ha observado que para ellas la migración ya no corresponde fundamentalmente a decisiones y motivaciones de orden familiar. En estos procesos de movilidad, las mujeres están encontrando posibilidades para reunirse con sus parejas, para mejorar su situación económica e incluso para 
modificar las condiciones de subordinación que han definido por muy largo plazo su vida en las comunidades rurales. Desde este cuestionamiento a la posición desventajosa de las mujeres en las estructuras familiares tradicionales, que es abundante en obligaciones y escasa en derechos, se propone analizar las migraciones femeninas actuales. Se empieza a constatar que las mujeres rurales casadas están migrando ya sea para reunirse con sus esposos o para abandonarlos; encontrar nuevas parejas; construir nuevas formas de convivencia conyugal; escapar de situaciones de violencia doméstica o trabajar y conseguir mejores condiciones de vida para sus hijos. Entre las solteras se detecta el deseo de salir de sus comunidades para trabajar y mejorar sus ingresos; evadir la obligación de ir a vivir con los suegros al momento de casarse; estudiar y conseguir otro tipo de pareja. E incluso, para las mujeres solas, como las madres solteras, abandonadas o divorciadas, que están a cargo de sus hijos, salir de sus comunidades es una importante opción. De tal suerte que en la actualidad, la migración para las mujeres rurales se está convirtiendo en una aspiración y opción personal, antes que familiar, que comienza a ser moldeada por demandas y necesidades específicas que dependen de su particular situación y del momento en que se encuentran sus vidas (Arias, 2013).

En este orden social rural de alguna manera subvertido, destacan los múltiples obstáculos que está encontrando la migración internacional masculina debido a las restrictivas políticas migratorias norteamericanas, incrementado sustancialmente los costos del traslado a través de la frontera. Ante ello, los varones del campo han tenido que quedarse en sus comunidades y emplearse en trabajos eventuales y con ingresos precarios. Esta situación contrasta con la relativa diversificación de la actividad económica femenina en los pueblos y que con el paso del tiempo se ha hecho indispensable para el sostén de sus familias. Por ello, muchas mujeres del campo que saben que sus ingresos ya no son complementarios a los de sus maridos, sino más bien el soporte de sus hogares, ya no piden permiso para salir a trabajar, cuestión que está contribuyendo a modificar la relación que establecen con sus esposos y los procesos de toma de decisiones (Arias, 2013).

Entre las mujeres más jóvenes del campo se está observando un cambio de actitud que se refleja en la resistencia a la norma tradicional de la residencia patrivirilocal que las obliga a trabajar para la familia del marido, así como en una genuina aspiración de construir relaciones de pareja más igualitarias, con mayor poder de negociación frente a sus maridos, evitando su sometimiento. De hecho, son cada vez más frecuentes los casos en los que las mujeres rurales recurren a las autoridades judiciales para renegociar las condiciones de la convivencia conyugal, incrementándose así las separaciones promovidas por las esposas que se encuentran inconformes con su situación conyugal. Sin embargo, es importante relativizar estos cambios puesto que en las comunidades sigue prevaleciendo mucha vigilancia y control social sobre las mujeres. Además de ello, existe todavía a nivel cultural, una fuerte resistencia a cambiar las representaciones sobre el papel de hombres y mujeres en la sociedad y respecto a la división sexual del trabajo. Si bien las mujeres rurales están respondiendo a la transformación de las 
condiciones de vida de sus comunidades, saliendo del ámbito doméstico para transitar al espacio público, viéndose obligadas a confrontar sus propias concepciones sobre la división sexual del trabajo tradicional —en la que los hombres eran los únicos o principales proveedores de sus hogares, detentaban la autoridad y tenían el derecho a subordinar y someter a sus esposas-, ellas continúan haciéndose cargo de las labores domésticas y del cuidado y la crianza de sus hijos. Todavía no se rompe del todo la fuerte asociación entre el espacio público (masculino) y el espacio doméstico (femenino), que sigue formando parte de las representaciones culturales sobre las identidades y las relaciones de género. Por lo tanto, puede decirse que la nueva situación de las mujeres rurales en el país se caracteriza por una gran contradicción entre los profundos cambios sociales y económicos ocurridos en el campo y la persistencia de representaciones y prácticas de género conservadoras de la tradicional división sexual del trabajo (González, 2005, 2014).

\section{Los sectores medios, urbanos}

y con alta escolaridad

Los estudios sociales sobre el desempeño de los hombres de sectores medios y de contextos urbanos en el ámbito familiar dan cuenta de que es muy probable que sus condiciones de vida y laborales, así como el elevado nivel educativo con que cuentan, sobre todo los más jóvenes, serían factores que posibilitarían una mayor flexibilización de su papel como padres y como esposos, además de modificar las valoraciones que tienen respecto a sus hijos. Entre estos varones se ha observado una mayor intensidad y tiempo destinado a los cuidados, la crianza y la formación de sus hijos. Para ellos, el nacimiento de sus hijos ha representado cambios en las rutinas diarias y un aumento en la actividad doméstica que requiere de su participación, así como trastornos en los horarios de su actividad laboral (Rodríguez y García, 2014; Vivas, 1996).

Entre estas jóvenes generaciones masculinas se ha observado un nuevo estilo de paternidad caracterizado por un mayor nivel de intimidad en la relación que establecen con sus hijos, y que se expresa en un incremento en el acercamiento emocional, una comunicación más directa y abierta, así como mayor expresión de sus afectos y sentimientos. Entre ellos, la nueva norma de relación paterna está basada más en la amistad y el compañerismo con sus hijos que en el ejercicio de autoridad. Este reajuste de las funciones paternas se encuentra acompañado de una actitud reflexiva y de ruptura consciente con el modelo de paternidad tradicional que padecieron cuando tuvieron que relacionarse con sus propios padres (Esteinou, 2008; García y Oliveira, 2006; Nava, 1996; Rojas, 2008b; Vivas, 1996).

La responsabilidad que estos varones asumen sobre sus hijos no es solamente respecto a su manutención y educación, sino sobre todo en cuanto a la atención que consideran han de brindarles. Por ello, en no pocos casos han comenzado a relativizar la importancia asignada a su actividad y horario laborales. El equilibrio que buscan establecer entre su actividad laboral y su vida familiar se encuentra muy relacionado con un criterio flexible que tienen en torno a la manutención de sus hogares, que se refleja también en modificaciones importantes en la toma de decisiones y en el ejercicio de poder en 
las relaciones familiares y conyugales (HernándezRosete, 1996; Rojas, 2008b; Vivas, 1996).

Estos hombres jóvenes de sectores medios no solamente están intentando asumir un rol de padre más expandido que el de proveedor económico de sus hogares, sino que además pueden compartir con sus compañeras la responsabilidad de la manutención de su familia, cuestionando abiertamente los mandatos culturales tradicionales del ideal paterno y de la masculinidad hegemónica. Existen hallazgos que muestran que algunos de estos varones han aceptado la alternancia en la proveeduría de sus hogares con sus compañeras durante ciertas etapas de su vida laboral marcadas por el desempleo. Esta actitud manifiesta una abierta aceptación respecto a la actividad extradoméstica femenina y a la contribución de las mujeres a la manutención del hogar (Hernández-Rosete, 1996; Rojas, 2008b; Vivas, 1996).

Coincide con esta manera de pensar aquella expresada por las mujeres de estos mismos sectores sociales, quienes consideran que su contribución monetaria es fundamental para la manutención de sus hogares. De hecho, ellas muestran una activa participación en la toma de decisiones familiares sobre la administración del presupuesto, la procreación y la educación de sus hijos. Además, tienen garantizada su libertad de movimiento y participación laboral e incluso política (García y Oliveira, 1994).

Es importante señalar que para las mujeres de clase media que combinan casa y empleo, el trabajo representa una opción de desarrollo personal y no tanto una necesidad económica imperiosa - como es el caso de las mujeres de sectores populares-, lo cual implica una ampliación de su horizonte simbólico. Para ellas, ahora es posible imaginar, escoger y llevar a cabo proyectos de vida que difieren claramente de las trayectorias tradicionales orientadas a la entrada al matrimonio a una cierta edad, seguida de la maternidad y el confinamiento a la vida doméstica. Son alternativas posibles para ellas el acceso a una educación superior y al mercado de trabajo, e incluso la vida en soltería. Con ello se ha relativizado el sentido que tenían los roles tradicionales de esposa, madre y ama de casa, elementos centrales en la definición de la identidad de las mujeres de las generaciones precedentes (Esteinou, 2008; Nehring, 2005).

Todos estos elementos contribuyen a entender por qué en estos contextos sociales y generacionales, el vínculo de pareja ya no parece descansar en un intercambio desigual de obligaciones, sino más bien en ideas sobre el amor romántico y el bienestar íntimo. Las relaciones interpersonales descansan cada vez más en ciertos grados de individualidad de ambos miembros de la pareja, así como en una mayor y más clara negociación de las obligaciones domésticas e incluso de las prácticas sexuales. Hombres y mujeres están intentando construir nuevas formas de relación conyugal más progresivas, abiertas y racionales, libres de las restricciones vividas por sus padres. El significado de la sexualidad tiende a residir en la experiencia de la intimidad y en la satisfacción mutua en lugar de la reproducción y la obligación de las mujeres de satisfacer a sus esposos como parte del acuerdo matrimonial. Como consecuencia, las prácticas reproductivas también se han modificado pues se empieza 
a retrasar el primer embarazo después del matrimonio, permitiendo a las parejas disfrutar de su compañía y buscar la estabilidad de la relación, al tiempo que se desea tener pocos hijos.

Por todo ello se considera que entre las jóvenes generaciones de estos ámbitos sociales las relaciones de pareja empiezan a ser más satisfactorias pero también más negociadas (Amuchástegui, 2001; Esteinou, 2008; Módena y Mendoza, 2001; Szasz, 2008).

\section{REFLEXIONES FINALES}

En el análisis que hemos realizado sobre los cambios en las relaciones de género de las familias mexicanas contemporáneas, nos percatamos de que el proceso de modernización y transformación de la vida privada ha sido desigual y está dando paso a la coexistencia de distintos regímenes normativos sobre las identidades genéricas y la división sexual del trabajo. Las nuevas concepciones no se extienden de manera generalizada ni uniforme sobre la sociedad en general y tampoco son integradas de manera nítida en el ámbito individual, puesto que los nuevos significados culturales se combinan con algunas nociones adquiridas a lo largo de la vida.

Las relaciones familiares, parentales y conyugales están registrando transformaciones generacionales pero con claras diferencias al considerar los estratos y grupos sociales, puesto que, tal como hemos observado, los cambios más significativos se restringen principalmente a los sectores sociales con mejores condiciones de vida, mayores niveles educativos y que residen en ámbitos urbanos. Al parecer, estos son elementos que condicionan las posibilidades de autonomía personal de hombres y mujeres, así como la resistencia a los mandatos de género y permiten la construcción de nuevas formas de relación entre los cónyuges y entre padres e hijos. Entre las jóvenes generaciones de las clases medias urbanas parecen predominar las ideas del amor romántico y de bienestar emocional, que permiten conformar uniones conyugales en las que existen mayores posibilidades de autonomía para las mujeres y de negociación entre ambos miembros de la pareja.

Los hombres y las mujeres jóvenes de estos contextos sociales han empezado a cuestionar los roles tradicionales en torno a la división sexual del trabajo. En el caso particular masculino se observan claros indicios de la expansión y modificación del papel de los padres, quienes manifiestan un alto compromiso y participación en la crianza de sus hijos. Los vínculos que establecen con sus pequeños crecen en intensidad y cercanía, al tiempo que desarrollan formas de comunicación y de entendimiento con ellos que antes no existían. Todos estos son rasgos de un estilo de paternidad más democrático en el cual la comunicación abierta y la demostración de afecto juegan un papel muy importante.

Estos jóvenes padres y esposos están abandonando el monopolio sobre la proveeduría y la toma de decisiones en sus hogares. Están intentando construir espacios de relaciones íntimas más igualitarias con sus hijos y con sus cónyuges, basadas en la confianza y la comunicación. Creemos que estas modificaciones están implicando una ruptura con el modelo de paternidad tradicional y están teniendo, forzosamente, un impacto en la construcción social de la identidad masculina de 
estos varones, que empieza a estar sustentada en nuevas valoraciones y normatividades.

Las nuevas formas de intimidad en las relaciones familiares de las clases medias en México están implicando mayor flexibilidad de roles no sólo en el plano de la división del trabajo — puesto que las mujeres se insertan cada vez más en actividades extradomésticas y participan en la proveeduría de sus hogares, en tanto que los hombres están más comprometidos con el cuidado y la crianza de sus hijos y pueden compartir la manutención familiar-, sino también en la estructura de autoridad y poder, ya que las mujeres han ganado mayores espacios y márgenes de autonomía y libertad. En este nuevo tipo de relaciones de pareja hay mayor equidad puesto que los márgenes de negociación entre hombres y mujeres ahora son más amplios.

En estos importantes cambios es notorio el papel desempeñado por las mujeres mexicanas pues, a pesar de los obstáculos que enfrentan cotidianamente, están contribuyendo a generar relaciones familiares y conyugales menos inequitativas. Esto es porque con su creciente nivel de escolaridad y empleo fuera del hogar, además de las posibilidades que ahora tienen para elegir a su pareja, para usar anticoncepción y, por lo tanto, para reducir su fecundidad, están experimentando importantes procesos reflexivos y de reconfiguración de su identidad de género.

En el México contemporáneo la vida cotidiana y las relaciones sociales en las parejas, las familias y de los padres con sus hijos están transitando hacia una nueva intimidad, conformando nuevos modelos de paternidad y conyugalidad. No obstante, dicha transición se ha dado de forma parcial, puesto que hasta ahora sólo ha involucrado a las capas sociales más favorecidas, dejando todavía al margen a amplios sectores de la población que se encuentran en situaciones más desventajosas en términos económicos y sociales.

En efecto, la elevada desigualdad social y económica prevaleciente en México y la consiguiente pobreza y segregación en la que se encuentra gran parte de la población que habita principalmente en contextos indígenas, rurales y marginados urbanos, contribuye a mantener vigentes patrones culturales tradicionales y marcadas expresiones de la desigualdad de género. En estos sectores sociales la vida de las personas, así como la convivencia familiar, conyugal y entre padres e hijos, continúan estando definidas por estructuras sociales e instituciones profundamente conservadoras como la Iglesia y el parentesco, que organizan las relaciones de género, estableciendo normas - claramente diferenciadas e inequitativas entre los hombres y las mujeressobre la división sexual del trabajo, la vida en pareja y los vínculos entre padres e hijos.

En estos contextos sociales la identidad de los hombres todavía permanece anclada a su papel como proveedores de sus familias. El deseo de trascender a través de los hijos, a quienes se considera elemento central de la vida matrimonial y familiar, se completa cuando los hombres son responsables de la manutención de sus hogares, lo que los coloca en el papel de jefes de familia y máxima autoridad. Para estos varones la paternidad y el trabajo remunerado son todavía elementos constitutivos y fundamentales de su identidad masculina, que otorgan sentido a su existencia cotidiana. 
En este tipo de poblaciones marginadas y empobrecidas, la persistencia del vínculo familiar y conyugal se fundamenta en la descendencia y en el intercambio de obligaciones entre los cónyuges. Mientras los hombres proveen protección y recursos económicos, las mujeres brindan atención a sus esposos y son responsables del trabajo reproductivo. No obstante, cabe señalar que en particular entre las jóvenes generaciones masculinas de sectores populares urbanos se detecta un esfuerzo por convivir de manera más cercana con sus hijos y participar en su crianza y cuidados, síntoma de su deseo por trascender el ideal paterno tradicional.

Es importante destacar que en ciertos contextos rurales e incluso urbanos empobrecidos, se comienza a observar el desarrollo de incipientes procesos de autonomía e individuación de las mujeres que ponen en cuestionamiento las estructuras de género y que no se originan desde un proceso de modernización social, económico y cultural — como es el caso de la población de sectores medios y escolarizados-, sino desde la propia precariedad y la desigualdad. En estos órdenes sociales trastocados por transformaciones que no necesariamente son modernizadoras, las mujeres se movilizan fuera del hogar para incorporarse en múltiples actividades, ya sea en las maquiladoras, las cooperativas, pequeños comercios o administrando las remesas enviadas por sus familiares. A través de su incorporación en estas ocupaciones ellas están adquiriendo una cierta libertad de movimiento y cierto poder frente a sus esposos que les permite participar más en las decisiones de sus hogares. Sin embargo, este empoderamiento es relativo, puesto que no las ha conducido a modificar sus roles domésticos tradicionales, ni tampoco las libra de las relaciones de violencia que sufren en el ámbito familiar.

Al respecto, es importante resaltar las diversas formas y mecanismos que adquieren las resistencias masculinas que buscan preservar el orden de género frente a las fuerzas sociales, económicas y culturales transformadoras. Uno de estos mecanismos es la segregación de los espacios socialmente diferenciados entre hombres y mujeres (públicos y privados; masculinos y femeninos) y el control que en esos espacios se ejerce sobre las mujeres para mantener su subordinación y con ello la persistencia del modelo tradicional de división sexual del trabajo (Ariza y Oliveira, 2004).

Otra forma de resistencia es el control masculino que todavía se ejerce en ciertos sectores sociales sobre la movilidad de las mujeres. Con ello se busca, sobre todo, impedir o dificultar la inserción femenina a la actividad económica y la posibilidad de que las mujeres obtengan recursos económicos. Hay que tomar en cuenta que la proveeduría constituye un eje fundamental de la valoración social masculina, a través de la cual los hombres ejercen control sobre la vida familiar, por lo que el empleo femenino es un elemento que puede cuestionar la predominancia masculina en sus hogares.

El control masculino sobre los recursos económicos de los hogares es otro mecanismo, quizá uno de los más importantes, que utilizan los varones impidiendo que sus esposas tengan información, acceso o poder de decisión sobre dichos recursos. En el ámbito nacional todavía un gran número de mujeres dependen económicamente de sus maridos, cuestión que las 
coloca en una situación de evidente subordinación y vulnerabilidad frente a ellos, y que implica una importante pérdida en su autonomía.

Y finalmente, la violencia como último recurso para restablecer el orden de género cuando los varones consideran que ha sido puesta en cuestionamiento de manera flagrante la supremacía masculina sobre la femenina. Al parecer, este mecanismo de control es particularmente frecuente entre los hombres de sectores populares urbanos y de ámbitos rurales e indígenas, quienes se encuentran en las posiciones más bajas de la estratificación social en el país. Dicha posición desventajosa respecto al resto de los varones, contribuiría a poner en duda su masculinidad, lo que explicaría muy probablemente que se aferren a su papel tradicional como proveedores de sus hogares para mantener el control en el ámbito familiar y la autoridad frente a su esposa y sus hijos. Cuando este orden se trastoca en contextos sumamente conservadores y precarios, emerge la violencia masculina en diversas formas, incluido el asesinato, para restaurarlo.»o 


\section{BIBLIOGRAFÍA}

Amuchástegui, Ana (2001), Virginidad e iniciación sexual en México. Experiencias y significados. México, The Population Council, Editorial EDAMEX.

Arias, Patricia (2013), "Migración, economía campesina y ciclo de desarrollo doméstico. Discusiones y estudios recientes", en Estudios Demográficos y Urbanos, vol. 28, núm. 1, pp. 93-121.

Ariza, Marina y Orlandina de Oliveira (2004), "Universo familiar y procesos demográficos”, en Marina Ariza y Orlandina de Oliveira (eds.), Imágenes de la familia en el cambio del siglo. México, Universidad Nacional Autónoma de México, pp. 9-45.

Arriagada, Irma (2010), "Familias sin futuro o futuro de las familias", en Susana Lerner y Lucía Melgar (coords.), Familias en el siglo XXI: realidades diversas y políticas públicas. México, Universidad Nacional Autónoma de México y El Colegio de México, pp. 53-113.

Bellato, Liliana (2001), "Representaciones sociales y prácticas de hombres y mujeres mazahuas sobre la sexualidad y la reproducción”. México, Centro de Investigaciones y Estudios Superiores en Antropología Social (CIESAS), tesis de maestría en antropología social.

CONAPO (Consejo Nacional de Población) (2006), La política nacional de población. Seis años de trabajo 2001-2006. México, CONAPO.

CONAPO (Consejo Nacional de Población) (2014), La situación demográfica de México. México, CONAPO.

CONEVAL (Consejo Nacional de Evaluación de la Política de Desarrollo Social) (2012), Informe de pobreza en México, 2012. México, CONEVAL.

Engle, Patrice y Cynthia Breux (1993), Is there a Father Instinct? Father's Responsibility for Children. Nueva York, The Population Council.

Esteinou, Rosario (2008), La familia nuclear en México: lecturas de su modernidad. Siglos XVI al XX. México, Centro de Investigaciones y Estudios Superiores en Antropología Social (CIESAS), Porrúa. 
García, Brígida y Orlandina de Oliveira (1994), Trabajo femenino y vida familiar en México. México, El Colegio de México.

García, Brígida y Olga Rojas (2004), "Las uniones conyugales en América Latina: transformaciones en un marco de desigualdad social y de género", en Notas de Población, núm. 78, pp. 65-96.

García, Brígida y Orlandina de Oliveira (2005), "Las transformaciones de la vida familiar en el México urbano contemporáneo", en Ximena Valdés y Teresa Valdés (eds.), Familia y vida privada ¿Transformaciones, tensiones, resistencias o nuevos sentidos? Santiago, Facultad Latinoamericana de Ciencias Sociales (FLACSO), pp. 77-106.

García, Brígida y Orlandina de Oliveira (2006), Las familias en el México metropolitano: visiones femeninas y masculinas. México, El Colegio de México.

García, Brígida y Edith Pacheco (2014), "Participación económica en las familias: el papel de las esposas en los últimos veinte años", en Cecilia Rabell (coord.), Los mexicanos. Un balance del cambio demográfico. México, Fondo de Cultura Económica (FCE), pp. 704-732.

García, Brígida y Orlandina de Oliveira (2014), "Familias, trabajo y políticas: encuentros y desencuentros", en Silvia Giorguli y Vicente Ugalde (coords.), Gobierno, territorio y población: las políticas públicas en la mira. México, El Colegio de México, pp. 195-232.

García Canclini, Néstor (1990), Culturas híbridas. Estrategias para entrar y salir de la modernidad. México, Grijalbo.

Giddens, Anthony (1998), La transformación de la intimidad. Sexualidad, amor y erotismo en las sociedades modernas. Madrid, Cátedra.

González, Soledad (2005), "Las mujeres y las relaciones de género en las investigaciones sobre el México campesino e indígena", en Elena Urrutia (coord.), Estudios sobre las mujeres y las relaciones de género en México: aportes desde diversas disciplinas. México, El Colegio de México, pp. 165-200.

González, Soledad (2014), "La feminización del campo mexicano y las relaciones de género: un panorama de investigaciones recientes", en Ivonne Vizcarra (comp.), La feminización del campo mexicano en el siglo XXI. Localismos, transnacionalismos y protagonismos. México, Universidad Autónoma del 
Estado de México, Plaza y Valdés Editores, pp. 27-45.

Gutmann, Matthew (1996), The Meanings of Macho: Being a Man in Mexico City. Berkeley, University of California Press.

Hernández, Daniel (2001), “Anticoncepción en México”, en José Gómez de León y Cecilia Rabell (coords.), La población en México. Tendencias y perspectivas sociodemográficas hacia el siglo XXI. México, Consejo Nacional de Población (CONAPO) y Fondo de Cultura Económica (FCE), pp. 271-306.

Hernández-Rosete, Daniel (1996), Género y roles familiares: la voz de los Hombres. México, Centro de Investigaciones y Estudios Superiores en Antropología Social (CIESAS), tesis de maestría en antropología social.

Instituto Nacional de Estadística y Geografía (INEGI) (2005), Población rural y rural ampliada en México 2000. México, INEGI.

Jamieson, Lynn (1999), "Intimacy Transformed? A Critical Look at the 'Pure Relationship"”, en Sociology, vol. 33, núm. 3, pp. 477-494.

Kaztman, Rubén (1991), Taller de trabajo: Familia, desarrollo y dinámica de población en América Latina y el Caribe: ¿Por qué los hombres son tan irresponsables? Santiago, Comisión Económica para América Latina y el Caribe (CEPAL), Centro Latinoamericano y Caribeño de Demografía (CELADE).

Lesthaeghe, Ron (1995), "The Second Demographic Transition in Western Countries: An Interpretation", en Karen Oppenheim y An-Magritt Jensen (eds.), Gender and Family Change in Industrialized Countries. Oxford, Clarendon Press, pp. 17-62.

López, María y Vania Salles (2006), "Los vaivenes de la conyugalidad”, en Rosario Esteinou (ed.), Fortalezas y desafios de las familias en dos contextos: Estados Unidos de América y México. México, Publicaciones de la Casa Chata y Sistema Nacional para el Desarrollo Integral de la Familia (DIF), pp. $385-435$.

López, Verónica (2014), “Autonomía femenina en contextos rurales. Análisis de los rezagos a partir de la Encuesta Nacional sobre la Dinámica de las Relaciones en los Hogares 2011 (ENDIREH)”. México, El Colegio de México, tesis de maestría en demografía. 
Módena, María Eugenia y Zuanilda Mendoza (2001), Géneros y generaciones. Etnografía de las relaciones entre hombres y mujeres de la ciudad de México. México, The Population Council, Editorial EDAMEX.

Mora, Minor y Orlandina de Oliveira (2014), “Introducción”, en Minor Mora y Orlandina de Oliveira (coords.), Desafios y paradojas. Los jóvenes frente a las desigualdades sociales. México, El Colegio de México, pp. 13-31.

Nájera, Alma, María López, Angélica Evangelista, Úrsula Zurita, Isaura Ortiz y Bertha Aparicio (1998), "Maternidad, sexualidad y comportamiento reproductivo: apuntes sobre la identidad de las mujeres", en Juan Guillermo Figueroa (comp.), La condición de la mujer en el espacio de la salud. México, El Colegio de México, pp. 275-305.

Nava, Regina (1996), "Los hombres como padres en el Distrito Federal a principios de los noventa". México, Universidad Nacional Autónoma de México (UNAM), tesis de doctorado en sociología.

Nehring, Daniel (2005), "Reflexiones sobre la construcción cultural de las relaciones de género en México", en Papeles de Población, vol. 11, núm. 45, pp. 221-245.

Núñez, Guillermo (2007), "Vínculo de pareja y hombría: 'Atender y mantener' en adultos mayores del Río Sonora, México", en Ana Amuchástegui e Ivonne Szasz (coords.), Sucede que me canso de ser hombre... Relatos y reflexiones sobre hombres y masculinidades en México. México, El Colegio de México, pp. 141-184.

Ojeda, Norma (1989), El curso de vida familiar de las mujeres mexicanas: un análisis sociodemográfico. México, Centro Regional de Investigaciones Multidisciplinarias (CRIM), Universidad Nacional Autónoma de México (UNAM).

Olavarría, José (2002), "Hombres: identidades, relaciones de género y conflictos entre trabajo y familia", en José Olavarría y Catalina Céspedes (eds.), Trabajo y familia: ¿conciliación? Perspectivas de género. Santiago, Servicio Nacional de la mujer (SERNAM), Facultad Latinoamericana de Ciencias Sociales (FLACSO), Centro de Estudios de la Mujer (CEM), pp. 53-76.

Olavarría, José (2004), “La invisibilidad de los hombres en la sexualidad y la reproducción y sus consecuencias en la responsabilidad. Notas para el debate”, en La fecundidad en América Latina: ¿Transición o revolución?, Serie Seminarios y conferencias, núm. 36. Santiago, CEPAL/CELADE, pp. 289-311. 
Oliveira, Orlandina de (1994), “Cambios en la vida familiar”, en Carta demográfica sobre México. DemoS, núm. 7, pp. 35-36.

Oliveira, Orlandina de (1998), "Familia y relaciones de género en México”, en Beatriz Schmukler (coord.), Familias y relaciones de género en transformación. Cambios trascendentales en América Latina y el Caribe. México, The Population Council, Editorial EDAMEX, pp. 23-52.

Plummer, Ken (2003), Intimate citizenship. Private Decisions and Public Dialogues. Seattle, University of Washington Press.

Rendón, Teresa (2004), "El mercado laboral y la división intrafamiliar del trabajo", en Marina Ariza y Orlandina de Oliveira (eds.), Imágenes de la familia en el cambio del siglo. México, Universidad Nacional Autónoma de México, pp. 49-87.

Rodríguez, Mauricio y Brígida García (2014), “Trabajo doméstico y de cuidado masculino”, en Brígida García y Edith Pacheco (coords.), Uso del tiempo y trabajo no remunerado en México. México, El Colegio de México, pp. 381-431.

Rojas, Olga (2007), "Criar a los hijos y participar en las labores domésticas sin dejar de ser hombre: un estudio generacional en la Ciudad de México”, en Ana Amuchástegui e Ivonne Szasz (coords.), Sucede que me canso de ser hombre... Relatos y reflexiones sobre hombres y masculinidades en México. México, El Colegio de México, pp. 519-561.

Rojas, Olga (2008a), "Reproducción masculina y desigualdad social en México", en Susana Lerner e Ivonne Szasz (coords.), Salud reproductiva y condiciones de vida en México, Tomo II. México, El Colegio de México, pp. 95-137.

Rojas, Olga (2008b), Paternidad y vida familiar en la Ciudad de México. México, El Colegio de México.

Rojas, Olga (2010), “Género, organización familiar y trabajo extradoméstico femenino asalariado y por cuenta propia”, en Revista Latinoamericana de Estudios de Familia, núm. 2, pp. 31-50.

Rojas, Olga y Mario Martínez (2014), "Uso del tiempo en el ámbito doméstico entre los padres mexicanos", en Brígida García y Edith Pacheco (coords.), Uso del tiempo y trabajo no remunerado en México. México, El Colegio de México, pp. 433-470. 
Schmukler, Beatriz (1998), “Comentarios finales” en Beatriz Schmukler (coord.), Familias y relaciones de género en transformación. Cambios trascendentales en América Latina y el Caribe. México, The Population Council, Editorial EDAMEX, pp. 541-552.

Szasz, Ivonne (1998a), "Los hombres y la sexualidad: aportes de la perspectiva feminista y primeros acercamientos a su estudio en México", en Susana Lerner (ed.), Varones, sexualidad y reproducción. México, El Colegio de México, pp. 137-162.

Szasz, Ivonne (1998b), "Sexualidad y género: algunas experiencias de investigación en México", en Debate feminista, vol. 9, núm. 18, pp. 77-104.

Szasz, Ivonne (2001), "La investigación sobre sexualidad y el debate sobre los derechos reproductivos en México", en José Gómez de León y Cecilia Rabell (coords.), La población de México. Tendencias y perspectivas sociodemográficas hacia el siglo XXI. México, Consejo Nacional de Población (CONAPO) y Fondo de Cultura Económica (FCE), pp. 365-397.

Szasz, Ivonne (2008), "Relaciones de género y desigualdad socioeconómica en la construcción social de las normas sobre la sexualidad en México”, en Susana Lerner e Ivonne Szasz (coords.), Salud reproductiva y condiciones de vida en México, vol. 1. México, El Colegio de México, pp. 429-473.

Vivas, María (1996), "Vida doméstica y masculinidad”, en María de la Paz López (comp.), Hogares, familias: desigualdad, conflicto, redes solidarias y parentales. México, Sociedad Mexicana de Demografía (SOMEDE), pp. 111-122.

Fecha de recepción: 30 de junio de 2015

Fecha de aceptación: 3 de diciembre de 2015 